\title{
Teachers' Perspectives on Professional Development in South Africa and Nigeria: Towards an Andragogical Approach
}

\author{
Oluwatoyin Ayodele Ajani \\ Edu-HRight Research Unit, \\ Faculty of Education, \\ North-West University, \\ Potchefstroom Campus, South Africa
}

DOI: https://doi.org/10.36941/jesr-2021-0070

\begin{abstract}
This study explored the perspectives of teachers in both South Africa and Nigeria on professional development using andragogical approach. The quality of teachers translates to the quality of the education system; this is why many African countries have been making a significant impact on the professional development of their teachers. A qualitative method approach was employed to explore the views of South African and Nigerian teachers on the professional development activities available to them. Adult learning theory was used as the theoretical framework to underpin this interpretive study. Data collection was through semi-structured face to face interviews with 6 Heads of Departments and semi-structured focus group interviews with 10 teachers from 16 high schools in both countries. The interviews were audio-recorded with permissions from the participants, further transcribed, coded and analysed through content thematic analysis. Findings from both countries revealed that though there were professional development programmes for teachers. However, they were inadequate and irregular for the teachers every year. The study, therefore, recommends appropriate professional development activities for teachers at least once a term. The study also recommends that these professional development activities should focus on the teachers' diverse classroom needs.
\end{abstract}

Keywords: classroom practices, perspectives, in-service professional development, continuity, appropriateness, regularity

\section{Introduction}

Over the past few decades, in South Africa and Nigeria, much attention has been given to teacher professional development. There is considerable evidence (Garet, Porter, Desimone, Birman, Yoon, 2001; Desimone, 2009; Brooke, Whitworth \& Chiu 2015; Gokmenoglu \& Clark, 2015) from across the world that indicates a clear shift from the traditional professional development programmes, that generally consists of fragmented workshops that lasts for an insignificant duration towards professional development activities that are more sustained, integrated and intensive in nature. Innovative approaches to professional development strive to improve teacher learning, their classroom practices and inevitably their learners' performance (Lieberman, 2008; Luft \& Hewson, 2014). In a large study (Garet, et al. 2001) conducted in the USA, using a national probability sample of 1,027 mathematics and science teachers, reveal that the core features of effective professional development activities that have a significant and positive effect on teachers must focus on content knowledge; opportunities for active 
learning and coherence with other learning activities.

Moreover, Bechel and Sullivan (2006) emphasise that PD should be more responsive to teacher's learning, specifically including content-specific learning opportunities that ultimately support teachers, such that they can draw important links between their PD, their school and classroom teaching. Thus, for this kind of PD to have an impact, the teacher ought to be viewed as a learner. Although there is a growing body of literature (Wei, Darling-Hammond \& Adamson, 2010; Penuel, Gallagher \& Moorthy, 2011; Stoll, Harris, \& Handscomb, 2012; Desimone \& Stuckey, 2014) that focuses on "best practices" in teacher professional development. However, relatively less systematic research evidence (Bechel \& Sullivan, 2006; Amour, 2010; Petrie \& McGee, 2012) has been conducted, whereby positioning and supporting teachers as "learners" over a sustained period integrating both school and classroom support. Thus, the purpose of this study was to explore the views about the in-service training teachers receive through professional development to teach Economics effectively in South African and Nigerian secondary schools. This study specifically explored the perspectives of teachers on professional development activities towards the use of andragogical approach to enhance their classroom instructional delivery, more specifically focusing on teachers as learners and teachers, thus playing a dual role.

\section{Theoretical Framework}

To understand the teachers' needs for in-service professional development activities and how these needs can be met, through quality and nature of professional development activities teachers access to enhance their classroom practices. This study is underpinned with the theory of andragogy. The rationale for the adoption of this adult learning theory is to understand the impact of different inservice professional development activities on the teachers' classroom practices in the education system.

Andragogy in this study, contextualised teachers' learning of new knowledge during in-service professional development activities as adult learning. Learning experience in this theoretical perspective sees a teacher as an adult learner who is matured, has his mind ready and set for what he wants to learn (Knowles, 1984).

Knowles (1980) in Ajani (2019) identifies four key assumptions that can promote appropriate learning in teachers as adult learners. These assumptions are:

(i) The adult learner needs to know why he needs to learn what he needs to learn. Teacher as an adult learner knows the purpose of his learning. This enables him to concentrate and give full attention to learn the new knowledge or acquire new skills. Attendance of teachers in professional development is motivated by the need to be in that activity instead of being at the classroom.

(ii) Learning is facilitated through experience. Firsthand experience or involvements in the acquisition of knowledge by teachers prompt teachers to gain lasting and quick learning through shared experience with others in professional development activities.

(iii) Learning is viewed as a problem-solving task. A range of activities is given to teachers to experience various professional development activities that are andragogical based. The experience here, aids teachers to also engage their classroom learners in tasks that are problem-solving tasks.

(iv) The relevance of the learning experience to classroom needs of the teacher, encourages the adoption of IPD activities into classroom practices, as immediate benefits of the professional development programme. Teachers want to know what and how their classroom practices can be improved before attending such professional development. These expectations enhance their learning as adults in in-service professional development programmes.

The theoretical framework integrates teachers' needs for in-service professional development to be integrated through adaptable approaches that will promote real learning in teachers. Knowles (1980) highlights four assumptions that propel the expected nature and patterns of needed in-service 
professional development activities that can enhance teachers' learning experience in professional development activities. These experiences at IPD centres apply to learning experiences in classroom situations if only contents of IPD activities are structured within andragogy theory which proposes:

- (a) Why do teachers need to learn something new? Teachers have concerns about improve their learners' academic performance through their enhanced classroom practices. This remains a significant reason why teachers are only interested in IPD that will promote their classroom teaching. Teachers need to be self-convinced of their attendance or participation in any IPD activity. Teachers may not be willing to participate in professional development programmes that do not impact their teaching skills. Teachers need professional development activities that can address their classroom challenges, needs and improve teaching methods as well as curriculum delivery.

- (b) Learning experientially: For in-service professional development activities to be effectively integrated into classroom practices, there is a need for teachers to experience knowledge and skills that can be adopted into classroom practices. Teachers as adult learners will appreciate professional development programmes that are experientially based (Oliveira, 2018). Teachers need to learn experientially, learning to them is effective and much appreciated if the facilitators of such professional activities are experienced, versatile and competent teachers from their specialized subjects. These facilitators build confidence in them as they know and proffer solutions to their classroom challenges and needs in their particular subjects of specialisation. Learning is made practical through active teachers' participation in the IPD.

- (c) Learning as problem-solving: Andragogy as a theory of learning promotes problemsolving skills among teachers during andragogical driven in-service professional development activities. Teachers need to access learning as problem-solving. It is a known fact that teachers require problem-solving skills in their instructional task delivery in schools. Activities that can make learners learn easily are what teachers look forward to in any in-service professional development activity. Varieties of these activities may enhance teachers to multi-task learners in their classroom practices.

- (d) An immediate benefit of the learning experience: In-service professional development activities that allow teachers active engagements in problem-solving tasks improve teachers' classroom experiences. Teachers learn effectively when knowledge is of immediate benefits to them. Teachers are ready to access or attend IPD activities that can be adopted or integrated into their immediate classroom practices regardless of the stress or distance of such IPD locations. Teachers will always be willing to attend such professional development activities that can improve their classroom teaching. They desire knowledge and skills that can be applied to classroom situations.

\section{Literature Review}

\subsection{International perspectives on teachers' professional development}

Teachers' in-service professional development programmes in most developed countries have been structured and highly funded to accommodate every teacher on a routine in-service professional development programme, to enhance classroom practices of the teachers; thus, in-service professional development programmes in these countries have significantly been of reference to African countries' models of in-service training (Steyn, 2008; Jita \& Mokhele, 2014; Harerimana, Ntahobavukira \& Adegoke, 2017; Jita, 2018).

Teachers in most Western countries are mandated to continue learning after their initial education, and to adapt to the changing classroom needs to enhance their learners' performance; such in-service professional development programmes are perceived as significant ways of improving quality education, through new knowledge and skills acquisition by the teachers (de Vries, Jansen \& van de 
Grift, 2013). Oliveira (2018) concurs that teachers' beliefs; habits, students' learning and the implementation of education reforms have a positive impact on teachers' perspectives on their participation in professional development programmes.

Similarly, Desimone and Garet (2015) reveal that professional development is more successfully effective when it is explicitly linked to classroom practices. It is perceived that in-service professional development programmes allow contextualisation of classroom practices by the teachers themselves to achieve desired learning in learners. Teachers should be developed on how to deliver lessons based on the varied subject/classroom situations to accommodate every learner through various and regular in-service professional development activities. Desimone and Stuckey (2014) suggest in-service professional development programmes that are content focused, provide active learning opportunities and are consistent with the school curriculum, teachers' knowledge, beliefs, and classroom needs as what teachers perceived to be the ideal in-service professional development programmes. The teachers oppose professional development programmes that are without active interactive participation with feedback.

With regards to teachers' participation in professional development, various international countries adopt different policies to ensure regular professional development of teachers at short intervals to enhance their productivity. In the United States of America, state laws and regulations mandate teachers to complete certain professional development activities to renew their teaching licenses, and also recent nationwide investments in teachers' in-service professional development to improve education system (Jacquith, Mindich, Wei, \& Darling-Hammond, 2010). Similarly, teachers in the United Kingdom and Germany are obliged to participate in professional development programmes, while Poland, Portugal, Spain, Slovakia and Slovenia have made teachers' participation in in-service professional development programmes optional except for career progression and salary increment. Contrarily, France, Iceland, Sweden and the Netherlands have made in-service professional development programmes to be the professional duty of teachers but are optional and not linked to career progression or salary increments (Scheerens, 2010). Teachers' perspectives on professional development programmes have an impact on the success of in-service professional development programmes all over the world. Teachers' professional development is career-long, job-embedded learning and their beliefs about learning and teaching determine their knowledge updating, reflection and collaborations in teachers' in-service professional development.

\subsection{South African and Nigerian Teachers' perspectives on professional development}

Effective in-service professional development programmes enable teachers to acquire the most needed and recent professional knowledge and skills that can enhance classroom practices as well as improve learners' academic performance. Concern for quality education has been a priority for several years in both South African and Nigerian schools (DoE, 2008, TRCN, 2010). This concern has led to the design of various in-service professional development activities to enhance teachers' classroom practices (Jita \& Ndlalane, 2009). According to Major (2015), high achieving education system around the world are those investing heavily in the professional development and learning of their teachers to enhance classroom performance.

Continuous development of teachers can promote significant improvement in classroom teaching and learning, and indeed learners' academic performance. Thus, attaining learning outcomes for the education systems in these countries. South African and Nigerian teachers have continued to be engaged in various professional development activities.

According to TRCN, (2010), SACE, (2010), registered teachers in both countries are mandated to improve their own learning experiences and develop themselves to improve their classroom practices through their participation in various professional development programmes. The teachers need to earn and accumulate 150 professional development points within three years from different types of inservice professional development activities (TRCN, 2010; SACE, 2010). Teachers Registration Council of Nigeria (TRCN) and South African Council of Educators (SACE) are statutory bodies responsible for 
the implementation, management, registration of teachers in education systems for the quality of the professional development system.

Studies have shown that teachers' in-service professional development is very complex, which explains why perspectives of teachers on their professional development activities for meaningful learning that can improve their classroom practices remain significant (Armour \& Makopoulou, 2012; Ushie, Akpan \& Okworo, 2015; Abbas \& Abdulwahab, 2017). The reason for different teachers' perspectives on their professional development may be linked to different classroom needs or contexts. This supports Steyn (2013) in his qualitative study where official documents on teachers' professional development were reviewed. He agrees that teachers need a dynamic model of professional development to accommodate their learning and their school environment for changed classroom practices.

Mokhele and Jita (2010) concur in their qualitative study of teachers who participated in the Mpumalanga Secondary Science initiative in South Africa, that participants for this professional development revealed that many in-service professional development programmes have not been implemented based on the understanding of the IPD from the perspectives of the participating teachers. The teachers also expressed dissatisfaction with the professional development activities they get.

Contrarily, Alade and Odebode (2014) in their quantitative study of 240 teachers as participants in Lagos, Nigeria, indicated that participants benefitted from the various in-service professional development activities they were exposed to. A similar study (Akpan \& Ita, 2015) of 500 teachers as participants in a quantitative study revealed that the participants claimed they benefited from in professional development activities they attended in Lagos, Nigeria.

Teachers' perspectives on the effectiveness of in-service professional development or need to attend any in-service training may depend on their motivation to attend. Archibald, Coggshall, Croft and Goe (2011) indicate that despite the good structures and opportunities for effective professional development programmes, they might prove to be inadequate if teachers are not motivated to attend such programmes. This is further explained by Price (2008) that teachers' feelings of being isolated in the planning or designing of in-service professional development activities affect their motivation to be engaged in such initiatives.

Similarly, Ravhuhali, Kutame, and Mutshaeni (2015) conclude in their mixed-method study of two hundred participants from both primary and secondary schools in Vhembe District of Limpopo, South Africa, that teachers have a positive perception towards their in-service professional development, although they are not being motivated adequately by stakeholders. Motivation plays a significant role in the effectiveness of teachers in such IPD activities and ultimately in their classroom practices. Ravhuhali et al (2015) agree that despite the benefits of IPD, South African teachers' perceptions varied on the impact of IPD on the classroom practices. This is evidently( Steyn, 2008) based on the inability of the teachers to critically reflect on their ability to try new solutions to solve problems in their daily classroom practices.

There is a need for teachers to be evaluated to determine their classroom needs for professional development programmes. According to Ogunrin (2011) in her quantitative study of 93 participants from 90 secondary schools across all the local government areas of Oyo State, Nigeria, the teachers indicated that there is an urgent need for in-service professional development activities to be reviewed and designed based on peculiar classroom needs of every teacher. This is further supported by Ajani (2019) that inservice professional development of teachers should not be one-size-fits-all activities. This, Ajani (2019) explains to be traditionally short term, incoherent and are often out of classroom contexts.

Conclusively, teachers' perspectives remain the same in both South Africa and Nigeria, the teachers believe they are not adequately being supported to attend or participate in in-service professional development programmes. Studies (Fareo, 2013; Ravhuhali,2014; Ravhuhali et al, 2015; Ushie, Akpan \& Okworo, 2015; Ugwu, Umeifekwem, Ofuebe, \& Didia, 2016; Ajani, 2019) have shown that teachers perceive that the Department of Education/Ministries of Education respectively in South Africa and Nigeria do not support teachers adequately on regular in-service professional development programmes. 


\section{Research Methodology}

The study adopted an interpretive qualitative approach to ascertain views about the in-service training teachers receive through professional development to teach Economics effectively in South African and Nigerian secondary schools. The rationale for specifically using this was to understand the world of the sampled participants (Cohen, Manion \& Morrison, 2011) through gaining insight and in-depth information into their backgrounds, beliefs and experiences (Creswell, 2014) best suited to the study. Semi-structured one-to-one interviews were conducted as they allowed participants to best voice their experiences, permitting them to describe and provide detailed information to the issue at hand (Creswell, 2014). While semi-structured focus interviews were advantageous since interaction among interviewees were able to yield the best information as they were similar to and cooperative with each other and were both cost and time effective. (McMillan \& Schumacher, 2014).

\subsection{Participants, Sampling and Setting}

The target population comprised secondary school Economics teachers from urban areas in South Africa (Southern Africa) and Nigeria (Western Africa). A non-probability sampling strategy was employed, specifically adopting a purposive sampling strategy as recommended by Welman, Kruger and Mitchel (2005) as it allowed to consider participants who happened to be accessible and who represented the targeted population, that have relevant information to achieve the objectives of the study and gather pertinent information to understand the central phenomenon, which in this case, to explore the views about the in-service training teachers receive through professional development to teach Economics effectively. The study was conducted in a selected District, which is one of the ten district municipalities within a province in one of the nine provinces in South Africa. The South African district has five circuits; Area 1 and Area 2 circuits were the sampled locations. Additionally, the study was also conducted in Location 1 and Location 2 Local government councils, representing Education Districts A and B within a state in Nigeria. The state has six education districts. Since this study is part of a much bigger study, and the focus of this paper is on the qualitative data, only five Economics teachers from the twenty sampled schools in South Africa and five Economics teachers from the sampled Nigerian secondary schools participated in the semi-structured focus group interviews; hence altogether two focus interview groups (five participants per group) were conducted, totalling ten participants. Additionally, semi-structured individual interviews were conducted with three Heads of Departments for Economics from each country; totalling six individual interviews for both South Africa and Nigeria.

\subsection{Procedures and Data Collection}

The schools targeted for data collection were all public schools in both South Africa and Nigeria; thus it was necessary to obtain permission from the respective education authorities before beginning data collection. Application to conduct research was submitted to the Department of Basic Education in the selected province in South Africa and the State Ministry of Education in Nigeria. The applications were successful, and permission was granted. Permission was also obtained from the principals of the sampled schools while convenient dates and times for both the semi-structured focus group and individual interview were scheduled with all the participants.

Semi-structured interview were specifically selected as an instrument as it allowed for further prompting and probing, pressing for clarity, rephrasing and summarising where necessary and checking for confirmation particularly if issues were vague Cohen, Manion \& Morrison, 2011). Concerning the semi-structured individual interview, it was divided into two sections, the first section requested participants' biographical data related to their highest qualification, years of management experience and the number of years they had taught Economics. The second section dealt with eight questions focusing on the nature and quality of in-service professional development provided to 
Economics teachers. This structuring of the interview also aided good interactions with the participants by making them feel comfortable and free to express their views. Concerning the semi-structured focus group, it was divided into two sections; the first was for the participants to provide their biographical data of qualifications, years of teaching experience and grade taught while the second section had nine questions which specifically focussed on the needs for the in-service professional development of Economics teachers and how these needs are met. The responses were recorded on audio-tape and were later transcribed verbatim for analysis. All ethical guidelines of informed consent, confidentiality, anonymity and voluntary participation were strictly adhered to during the process of data collection. Participants were duly briefed, assured of confidentiality and anonymity as well as a voluntary withdrawal at any stage of the study.

\subsection{Data Analysis}

Qualitative data analyses were carried out using thematic analysis. This process entailed the interpretation of qualitative data in easy interpretable and concise descriptions of emerging themes and patterns within the dataset (Braun \& Clarke, 2006). Specifically, data from the semi-structured focus groups and individual interviews were transcribed; the thematic analyses involved verbatim transcripts of both. According to Brune and Clarke (2006), six simple steps are used to analyse the data about the research questions: (i) familiarisation with available data, (ii) generating initial codes, (iii) searching for themes, (iv) reviewing the generated themes, (v) defining and naming themes, and (vi) producing the report. Atlas.ti was used to facilitate systematic, efficient coding and complex analyses of the qualitative data that was collected. Each theme generated conclusions that were based on the findings from the study (Maree \& Pietersen, 2010).

\section{Findings and Discussion}

Findings from the qualitative data expressed the views of the teachers and their Heads of Departments on the existing in-service professional development activities in both South Africa and Nigeria. Following themes emerged from the analysis of the transcriptions: With excerpts from South African teachers (Dumiso, Phindile, Thabo, Buhle, and Nonjabulo), South African Heads of Departments (Khumalo, Ntabee, and Matadi); Nigerian teachers (Angela, Fatai, Kunle, Abu, James), Nigerian Heads of Departments (Adamu, Chinedu, and Abioye). These names were pseudonyms.

\subsection{Contextualising the investigation}

This section is introduced to contextualise the investigation. The schools are located in the urban areas of both countries. The participants were Economics teachers and Economics teaching Heads of Departments in some selected schools in a province of South Africa and a State in Nigeria. The findings show that all the participants were qualified and experienced. The highest qualification of the participants was M.Ed., and the lowest was NCE/ACE. The participants have attended different inservice professional development activities in the last four years.

\subsection{Theme 1: Adequacy, Regularity and interval of IPD}

Participants in both countries admitted to having attended or participated in a series of in-service professional development activities which were school-based or off-site based. However, their views on the adequacy, regularity and frequency of these IPD activities indicate that these in-service professional development activities are not adequate, neither are they regular and the interval between the IPD activities are not satisfactory to them. Teachers, as well as their HoDs, perceived that IPD activities made available to them every year were grossly irregular. They believed that they needed more IPD every year to promote their classroom efficiency. Several responses were indicated on the 
irregularity of teachers' IPD.

Participant Dumiso decried that professional development programmes are few per year: "We attend two times a year. At the beginning of the year and toward the end of the year". In a similar view, participant Fatai supported further: "I have only attended two times in the last five years! It is so unfortunate that our government does not provide enough professional development activities to us every year, most times, they concentrate on teachers teaching Mathematics, English and other Science subjects. Even to these, the IPD activities are still not frequent to teachers".

Gokmmenoglu and Clark (2015) in their study of 1730 participants in Turkey revealed that inservice professional development remains inadequate to teachers despite the importance of professional development to support education reforms and improve classroom performance of teachers. Similarly, Desimone and Stuckey (2014) indicate that regular participation of teachers in professional development programmes does not only improve their instructional delivery but also enhance learners' academic performance and ensure quality in the education system. Teachers who engage in regular and adequate in-service professional development programmes at short interval improve their teaching skills and teach better in schools (Ravhuhali, Kutame \& Mutshaeni).

Participants agreed that teachers' in-service professional development programmes are not limited to schools alone, teachers attend professional development programmes at venues outside the school premises which are known as off-site based professional development programmes. Participant Ntabee highlighted: "I will start with outside the school, normally in the year, we have two workshops which are organized by the Department of Education (DoE) and in the school, we have got two, which are subject meetings during which our department plans. This means four in all". Similarly, participant Khumalo explained further: "There are many, maybe three. One within the school, the two was off-site". Participant Chinedu explicitly described the modes by which teachers are being professionally developed: "We organize the off-site in-service training at least one for each department in a year, let me say in the last three years we must have organized like three on-school IPD activities and the Education Districts do organize off-site training for the teachers in all the departments".

Inference from this suggests that classroom practices of the teachers may be affected with inefficiencies. According to Fareo (2013), teachers can only be effective in classroom instructional delivery if they experience IPD activities regularly at a short interval. Teachers perceive that in-service professional development programmes enable them to acquire new knowledge, ideas and skills that enhance their classroom practices only when they are given the opportunities to frequently participate in professional development programmes at a regular interval (Ravhuhali, 2014). It is also noted that failures in curriculum delivery and implementation can be traced to inadequate professional development opportunities to teachers (Govender, 2018).

\subsection{Theme 2: The needed content focus of in-service professional development}

This theme identified what teachers wanted as IPD structures. Teachers are in the best position to indicate what they want as their professional needs. They wanted IPD activities that could help their learners and enhance their classroom practices. Findings from most participants from both countries indicated that the existing in-service professional development programmes were not satisfactory to the teachers.

Their views highlighted the grudge on the duration, time, and content focus of the existing professional development programmes that have attended: "Haaaa... I think we should have it two times in.... a term so that if we are looking at a certain chapter or topic, we try to link what is happening around us to that chapter or topic so that learners can understand and link what is happening in the country for now" (Phindile). The participant wanted content-focused programmes that will be frequent to them: "We need IPD activities that will be frequent and have adequately, the contents of what we teach in every topic, we normally waste time on what is not necessary like analysis of past results, we should focus on how to mark and what is expected of the learners in the examinations and how to use the standard marking to train the learners" (Dumiso). 
Participant Phindile specified the structure of ideal in-service professional development teachers can appreciate: "I think it must be done at the beginning of the term and closing of the term and closing of the term. And it must not be only one day; I think two days will be fine to cover everything that will be taught in that term. It must be around where we are". Similarly, another participant declared emphatically that the teachers should be the ones to indicate what or how their professional development programmes should be structured or designed to address their classroom needs: "We should be the ones to say the types of training we need that can help us, sometimes they bring all teachers together for "one size fits all" training which does not help our classroom teaching, we need to be assessed to know what we need, and also we want a workshop that will treat or teach us how to teach difficult topics successfully in our schools. What we don't have, we cannot give, that is why we need to be trained and re-trained every term to be fit for the responsibilities" (Angela).

A similar opinion was shared by participant Abu: "It should be on a sessional basis and the focus should be content-based. I prefer if it is content-based rather than just going through the results alone. For continuity, I will love it to be continued but the way it is structured should be looked into. For convenience sake, I will prefer it to be two in a session so that each session we can brainstorm together as teachers before another session. For accessibility, if it is subsidized it will be accessed by more teachers". Calls for content-focused of in-service professional development have been established by various studies (Garet, Porter, Desimone, Birman \& Yoon, 2001; Desimone, 2009; Wei, DarlingHammond, \& Adamson, 2010; Desimone \& Stuckey, 2014; Luft \& Hewson, 2014; Whitworth \& Chiu, 2015).

However, to know the contents of in-service professional development programmes that teachers will appreciate, there is a need for teachers to be observed in their classroom practices to assess their professional needs in addition to what the teachers will request as professional needs: "Teachers' input is needed. A teacher may be weak in the Econometric aspect of Economics so when you ask for the input of teachers, that will benefit. Teachers know the areas where they have challenges in their classroom teaching, the classroom situations and learners' focus are important to teachers" (Abioye). Participant Ntabee corroborated further: "I think we need to be consulted or assessed, to know our problems in teaching Economics in every grade; for us teaching grade 12, there are some topics we would appreciate if they can be taught in IPD classes for us to understand and apply to our learners".

The findings on this theme suggest that teachers need to be consulted or assessed to determine what kind of IPD activities will enhance their classroom practice. These comments support several other studies that teachers' in-service professional development programmes must be contextualised to teachers' classroom needs (Guskey, 2002; Stoll, Ogunrin, 2011, Harris, \& Handscomb, 2012; Ravhuhali et al, 2015; Ajani, 2019b). Teachers will be motivated to attend IPD activities that have their inputs or learning expectations that can improve their classroom practices for better performance.

\subsection{Theme 3: Funding for teachers to attend IPD activities}

Regular funding to attend in-service professional development programmes especially the off-site activities are perceived as positive support from School Management Teams by the teachers. Teachers wished they could be supported with adequate fund to attend IPD activities. They condemned act where they used their own money to attend IPD activities, some claimed that in some schools' teachers could be funded base on personality in the schools.

Participant Phindile condemned the partisan support to teachers on this: "The Department of Education will organize the venues, in my school; we use our money to fund ourselves. The school only gives those who have cars money for petrol, if you don't have cars, you don't get anything. This is a challenge for us, especially if you are newly employed and it will take six months before you get paid".

While another participant concurred: "The Department organizes the venues, bring the subject advisors. The school refunds our petrol money if you go with your cars" (Nonjabulo). In some instances, teachers got supported with fund while at another time they were responsible for their transportation to the in-service training venues: "It has been like 50-50. There were some, I paid for and there were some, 
my employer paid" (James).

Participants want government or SMTs to be responsible for their transportation to locations for IPD: "It's quite unfortunate that teachers have to attend IPD activities on their bills, the ones I have attended, I had to take care of myself. I want the government to provide us fund to attend through our schools, or the SMT should be mandated to be responsible for this" (Chinedu).

Adequate provision of the fund will encourage teachers to attend IPD activities regularly; this will support or encourage teachers. According to Ravhuhali, Kutame and Mutshaeni (2015) teachers need to be supported to attend continuous professional development to improve their skills. Funding of teachers to participate in professional development activities may be seen by some teachers as motivation and readiness to acquire new skills and knowledge to improve classroom practices (Archibald et al, 2011).

\section{$5 \cdot 5$ \\ Theme 4: Monitoring and follow-up for implementation of IPD}

Monitoring of teachers to follow-up on what they have learnt from IPD activities for implementation in their classroom remains an important aspect of professional development. Monitoring or follow-up indicates feedbacks on teachers' in-service professional development programme; feedbacks encourage reviews of professional development for improvement or achievement of goals of IPD.

Across both South Africa and Nigeria, participants expressed their dissatisfaction with the available monitoring and follow up mechanism as grossly inadequate: "Yes, the DoE follow-up to check if those things mentioned in the workshops have been implemented. They come to schools to check but not regularly, at least once a term to check curriculum coverage, learners' notes, other files and records" (Khumalo). In the same manner, participant Matadi concurred: "Yes, the subject advisors come to school to check. They do follow up; they check the documents, learners' materials and others but follow up on IPD activities are not regular".

Inconsistency visits of the appropriate government authorities to monitor and follow-up on teachers to ensure the effectiveness of IPD or how teachers can further be assisted on professional development remains a significant challenge to professional development: "No, the District officials just come maybe at the end of the year whether the learners passed or teachers are doing well. The training conducted in the schools are monitored, we check to see if the teachers are doing what we taught them. We have one on one discussion to support the weakness of the teachers after observation in the classes" (Adamu).

Contrastingly, Participant Abioye declared that the task of follow -up or monitor has been taken over by SMTs: "Follow-up is a problem! It's only the school-based training that the principals, viceprincipals and HoDs go round to monitor or follow-up the teachers to ensure they are practising what they were taught, the teachers are observed to assess changes in their classroom practices by the VicePrincipals and HoDs".

Findings indicate that monitoring of teachers in this aspect has been a big challenge in both countries. According to Ravhuhali, et al (2015), teachers' professional development should be evaluated after some time to get feedback. Desimone and Garet (2015) recommend periodic monitoring and feedbacks that can help in creating a continuous cycle of improvement. There is a need for consistent feedbacks to analyse or make presentations on the effectiveness of in-service professional development programmes on both teachers and their learners (Desimone \& Stuckey, 2014; Ravhuhali et al, 2015; Ajani, 2019).

The results of this study indicate that teachers can always provide and promote quality teaching and learning in their classrooms through efficient professional development. In-service professional development of teachers is a vital part of educational policies that can enhance improvement in learners' performance in our schools (Jita and Mokhele 2014). Teachers are aware of the implications of IPD programmes to their classroom practice, they agree that it can help them to acquire new skills, more knowledge and better teaching approaches to deliver their subject-contents effectively in their classroom to promote learners' academic (Ravhuhali, 2014). 


\section{Implications of the Study}

Based on the findings from the participants, this study, therefore, proposes the following recommendation to enhance the professional development of teachers in both South African and Nigerian schools, and to the other developing African countries.

\subsection{Assessment of teachers' classroom needs}

There is a need for regular assessment of the classroom needs of the teachers before designing or enrolling them for any professional development. Teachers should be observed and assessed by experienced subject specialists during classroom instructional delivery before and after recommended professional development training or activities. The assessment can also be done by the heads of departments, the deputy principals, the principals and the subject advisors.

\subsection{Monitoring}

Teachers should be monitored after participation in any professional development activity to ensure that they put into classroom practices the acquired knowledge and skills. The monitoring will also ensure teachers' active participation in the professional development for possible transmission to their classroom practices.

\subsection{Adequate and regular professional development}

The regular participation of teachers in various professional development is critical to enhancing learners" performance. Monitoring tools should be designed for this and effectively used. It will be helpful to the teachers, if they are made to attend professional development at least once every term, preferably at the beginning of the term to prepare the teachers for the curriculum delivery for every term.

\subsection{Funding}

Teachers should be funded to attend professional development. Adequate funding should be made available to schools and all teachers to participate in various training. An adequate fund should also be made for the school management to design school-based professional development activities for their teachers. On-spot training enables the teachers to be trained or developed according to the situational analysis of every school.

\subsection{Subject-based training and practical teaching session}

It is recommended that the professional development of teachers should be designed based on their subjects, 'one-size-fits-all' type of professional development does not allow teachers to learn as adult learners. The use of subject-based training also allows teachers to observe experienced teachers teaching some difficult topics from their subject curriculum. Observation of others while teaching is known as lesson study which allows the teachers as learners to observe, ask questions and acquire a better approach to curriculum delivery in classrooms.

\section{Conclusion}

The study focused on the perspectives of teachers on various professional development activities they access in both South Africa and Nigeria. Teachers' professional development is significant to classroom practices of the teachers, which invariably influence learners' academic performance. The quality of 
teachers also manifests into the quality of education through the curriculum implementation in these countries. Reviewed studies revealed that professional development of teachers in most developed countries is heavily invested and the professional development activities for these teachers are highly productive as the classroom needs of the teachers are usually the focus of the professional development. However, a review of related studies on professional development activities in African countries indicated inadequate support for teachers on professional development.

Findings from this study also revealed that teachers in both countries do not access professional development activities regularly and adequately. The findings also indicated that the professional needs of teachers are not assessed before designing various professional development activities. The Participants also condemned the use of 'one-size fits all' professional development activities for them. Lack of financial support for teachers to attend professional development activities was also identified by the teachers.

The perspectives of teachers on various professional development activities through andragogical approach were also indicated by the participants as an effective approach to enhance their classroom practices and for curriculum implementation in their schools. The design of various existing professional development activities does not cater for diverse subjects or situational analysis of the schools, where teachers can learn as learners to acquire skills and knowledge that can be easily adopted by their learners, to adapt to diverse realities in their classroom contexts.

\section{References}

Abbas, A.G., \& Abdulwahab, S. (2017). Matching Teacher production with National Needs in Nigeria: A periscope, IOSR Journal of Humanities and Social Science, 22(3), 20-25.

Ajani, O.A. (2019). Effective Teachers' Cluster System as an Approach to Enhanced Classroom Practices in South African High Schools, Journal of Gender, Information and Development in Africa (JGIDA), 8(1), 173-193.

Ajani, O.A. (2019b). Understanding Teachers as Adult Learners in Professional Development Activities for Enhanced Classroom Practices, AFFRIKA Journal of Politics, Economics and Society, 9(2), 195-208.

Akpan, C.P., \& Ita, A.A. (2015). Teacher professional development and quality universal basic education in Lagos State, Nigeria, Global Journal of Arts and Humanities and Social Sciences, 3(9), 65-76.

Desimone, L. M., \& Garet, M. S. (2015). Best practices in teachers' professional development in the United States. Psychology, Society and Education, 7(3), 252-263.

Desimone, L., \& Stuckey, D. (2014). Sustaining professional development. In. L. Martin, S. Kragler, D. Quatroche, \& K. Bauserman (Eds.), Handbook of professional development in Education: Successful Models and Practices, Prek-12 (pp. 467-482). New York, NY: Guilford Publications.

Eldridge van Niekerk, E., \& Muller, H. (2017). Staff perceptions of professional development and empowerment as long-term leadership tasks of school principals in South African school: an exploratory study, African Education Review, 14(3-4), 93-110.

Fareo, D.O. (2013) Professional development of teachers in Africa: A case study of Nigeria, The African Symposium, 13(1), 63-68.

Garet, M. S., Porter, A.C., Desimone, L., Birman, B. F., \& Yoon, K. S. (2001). What Makes Professional Development Effective? Results from a National Sample of Teachers, American Educational Research Journal, 38(4): 915-45.

Gokmenoglu, T., \& Clark, C.M. (2015). Teachers' evaluation of professional development in support of national reforms. Issues in Educational Research, 25(4), 442-459.

Govender, S. (2018). South African teachers' perspectives on support received in implementing curriculum changes, South African Journal of Education, 38(2), S1-S12.

Inken G., Kim S., \& Jan T. van der Veen (2017). Team-Based Professional Development Interventions in Higher Education: A Systematic Review, Review of Educational Research, 87(4): $736-767$. https://doi.org/10.3102/o034654317704306.

Jita, L.C. \& Ndlalane, T.C. (2009). Teacher clusters in South Africa: Opportunities and constraints for teacher development and change, Perspectives in Education, 27(1), 58-68.

Mkhanazi, S. (2014). Crossing the past political boundary: teacher professional learning in a South African Reform context, Mediterranean Journal of Social Science, 5(10), 425-432.

Mphahlele, L.K. (2012). School cluster system: A qualitative study on innovative networks for teacher development, Procedia - Social and Behavioral Sciences, 47 (2012) 340-343. 
Ogunrin, A.B. (2011). Perception of Nigerian Teachers about In-service Capacity Development: An Empirical Field Sample Report on Oyo State, Nigeria, Journal of Alternative Perspectives in the Social Sciences, 3(3), $743-757$.

Ogunyinka, E.K., Okeke, T. I., \& Adedoyin, R.C. (2015). Teacher Education and Development in Nigeria: An analysis of reforms, challenges and prospects, Educational Journal, 4(3), 111-122.

Okobia, E.O. (2013). The Effects of In-service Education on Teachers' Knowledge of Junior Secondary School Social Studies Curriculum and Instruction in Delta State, Nigeria, IOSR Journal of Research E Method in Education, 2(6), o1-o8.

Ono, Y., \& Ferreira, J. (2010). A case study of continuing teacher professional development through lesson study in South Africa, South African Journal of Education, 30: 59-74.

Osamwonyi, E.F. (2016). In-service education of teachers: overview, problems and way forward, Journal of Education and practice, $7(26), 83-87$.

Petrie, K., \& McGee, C. (2012). "Teacher Professional Development: Who is the learner?" Australian Journal of Teacher Education, 37(2): Article 4. Available at: http://ro.ecu.edu.au/ajte/vol37/iss2/4.

Ravhuhali, F., Kutame, A. P., \& Mutshaeni, H.N. (2015). Teachers' perceptions of the impact of continuing professional development on promoting quality teaching and learning, International Journal of Education Science, $10(1), 1-7$.

Steyn, G.M. (2013). Building professional learning development in South African schools. Anthropologist, 15(3), 277289 .

Stoll, L., Harris, A., \& Handscomb, G. (2012). Great professional development which leads to consistently great pedagogy: nine claims from research. Nottingham: NCTL

Tanang, H. (2014). Teacher Professionalism and Professional Development Practices in South Sulawesi, Indonesia. Journal of Curriculum and Teaching. 3(2), 25-42. https://doi.org/10.5430/jct.v3n2p25.

Tsotesi, C.T., \& Mahlomaholo, S.M.G. (2013). Teacher professional development: what is missing? Journal of Educational Studies, 12(1), 89-102.

Ugwu, C.U., Umeifekwem, J.E., Ofuebe, J.I., \& Didia, S.I. (2016). A Descriptive Analysis of Teachers' Professional Competencies Needed for Academic Activities in Educational Institutions in Nigeria, Researchjournali's Journal of Education, 4(2), 1-8.

Ushie, B.C., Akpan, S.J., \& Okworo, G.S (2015). Continuing professional development of primary school teachers: Panacea for the emergence of globally competitive Nigerian learners, Sky Journal of Educational Research, 3(3), $032-036$.

Wei, R. C., Darling-Hammond, L., \& Adamson, F. (2010). Professional development in the United States: Trends and challenges (Vol. 28). Dallas, TX: National Staff Development Council.

Whitworth, B. A., \& Chiu, J.L., (2015). Professional Development and Teacher Change: The Missing Leadership Link, Journal of Science Teacher Education, 26(2), 121-137. https://doi.org/10.1007/s10972-014-9411-2. 